\title{
Arbuscular mycorrhizal fungi improved plant growth and nutrient acquisition of desert ephemeral Plantago minuta under variable soil water conditions
}

\author{
ZhaoYong $\mathrm{SHI}^{1,2,3^{*}}$, Bede MICKAN ${ }^{3}$, Gu FENG ${ }^{2}$, YingLong $\mathrm{CHEN}^{3,4}$ \\ ${ }^{1}$ College of Agriculture, Henan University of Science and Technology, Luoyang 471003, China; \\ ${ }^{2}$ College of Resources and Environmental Sciences, China Agricultural University, Beijing 100094, China; \\ ${ }^{3}$ School of Earth and Environment, the University of Western Australia, Crawley, WA 6009, Australia; \\ ${ }^{4}$ State Key Laboratory of Soil Erosion and Dryland Farming on the Loess Plateau, Institute of Soil and Water Conservation, \\ Chinese Academy of Sciences and Ministry of Water Resources, Yangling 712100, China
}

\begin{abstract}
Desert ephemeral plants play an important role in desert ecosystem. Soil water availability is considered as the major restrictive factor limiting the growth of ephemeral plants. Moreover, arbuscular mycorrhizal fungi (AM fungi) are widely reported to improve the growth of desert ephemerals. The present study aimed to test the hypothesis of that AM fungi could alleviate drought stress of desert ephemeral Plantago minuta, and AM fungal functions reduced with the improvement of soil water content. A pot experiment was carried out with three levels of soil water contents $(4.5 \%, 9.0 \%$, and $15.8 \%(\mathrm{w} / \mathrm{w})$ ), and three AM inoculation treatments (Glomus mosseae, Glomus etunicatum and non-inoculation). The results indicate that mycorrhizal colonization rate decreased with the increase of soil water availability. Inoculation improved plant growth and N, P and K acquisition in both shoots and roots regardless water treatments. When comparing the two fungi, plants inoculated with $G$. mosseae performed better than those inoculated with $G$. etunicatum in terms of plant growth and nutrient acquisition. These results showed that ameliorative soil water did not suppress arbuscular mycorrhizal fungal functions in improving growth and nutrient acquisition of desert ephemeral Plantago minuta.
\end{abstract}

Keywords: Plantago minuta; soil water availability; nutrient acquisition; desert ephemeral; Junggar Basin

Citation: ZhaoYong SHI, Bede MICKAN, Gu FENG, YingLong CHEN. 2015. Arbuscular mycorrhizal fungi improved plant growth and nutrient acquisition of desert ephemeral Plantago minuta under variable soil water conditions. Journal of Arid Land, 7(3): 414-420. doi: 10.1007/s40333-014-0046-0

Desert ephemeral plants are specially adapted to harsh desert environments. Generally, they remain dormant until a rare rainfall event occurs where they emerge with the appearance of short, wiry grasses and delicate flowers. These plants grow and flower quickly before the desert soil dries up again. Desert ephemeral plants usually have a very short epigeous phase ranged from 40 to 90 days with a mean of 76 days (Mao and Zhang, 1994; Zhang and Chen, 2002; Ramawat, 2010).

In China, desert ephemeral plants are mainly distributed in North Xinjiang with the easternmost limit at the eastern edge of the Junggar Basin (Mao and Zhang,
1994). In Junggar Basin, ephemerals emerge in March and disappear between May and June. In early spring, ephemeral plants are dominant in the plant community and form a synusia, with the fresh weight of ephemerals accounting for over $60 \%$ of the total community yield (Zhang and Chen, 2002). Ephemerals play a key role in dune stabilization and can reduce the intensity of wind erosion (Wang et al., 2003) and desert ecosystem stability (Qian et al., 2007; Wang et al., 2009).

Desert soil is typically deficient in soil water availability and nutrients. For example, the mean

*Corresponding author: ZhaoYong SHI (E-mail: shizy1116@gmail.com)

Received 2014-07-17; revised 2014-09-15; accepted 2014-10-15

(C) Xinjiang Institute of Ecology and Geography, Chinese Academy of Sciences, Science Press and Springer-Verlag Berlin Heidelberg 2015 
annual precipitation ranges from 100 to $200 \mathrm{~mm}$ with a high surface evaporation of 1,000-1,700 mm (Wang et al., 2003). Soil water contents in soil layer of 0-30 $\mathrm{cm}$ are $2 \%-5 \%$ and the available $\mathrm{P}$ is less than 2 $\mathrm{mg} / \mathrm{kg}$ soil (Wang et al., 2004; Shi et al., 2013). Ephemeral plants can survive and complete their life cycles in such harsh conditions. Therefore, to explore the adapted strategies of ephemeral plants under desert conditions has trigged the interest of the scientific community (Lan and Zhang, 2008; Yuan and Tang, 2010).

Arbuscular mycorrhizal fungi (AM fungi; Phylum Glomeromycota) are significant members of the soil microbial community, which form symbiotic relationships with the majority of higher plants (Smith and Read, 2008). AM fungi are important components of virtually all terrestrial ecosystems and are especially critical in improving plant nutrient and water uptake under semi-arid conditions (van der Heijden et al., 2006; Allen, 2011). AM fungi can improve plant resistance to soil water deficit (Lambers et al., 2008; Smith and Read, 2008; Apple, 2010; Ruiz-Lozano and Aroca, 2010). The underlying mechanisms are most likely to be a combination of nutritional and non-nutritional host-plant benefits. Non-nutritional mechanisms may include: (1) hormonal effects (particularly abscisic acid) due to mycorrhizal colonization; (2) direct water uptake by improved soil-hyphal contacts (especially important during soil drying) leading to more effective scavenging for water in micropores; and (3) increased photosynthesis through sink stimulation (Kaschuk et al., 2009; Smith et al., 2010). There is also evidence of plant interconnectivity facilitated by AM fungi connecting plant roots via a common mycorrhizal network, where inter-plant resources are transferred through the network along a source-sink gradient (Kiers et al., 2011). Augé (2004) investigated mycorrhizal network ability to alter moisture retention properties of soils through an increase in soil aggregation, such that non-mycorrhizal plants growing in a mycorrhizal soil benefit through enhanced plant water availability.

In Junggar Basin, the majority of desert ephemerals form mutualisms with AM fungi (Shi et al., 2006, 2007; Zhang et al., 2011, 2012a, b), and mycorrhizal colonization increased plant growth, nutrition uptake, productivity and community restoration (Chen et al., 2008; Sun et al., 2008; Zhang et al., 2011, 2012a).
However, the major factor limiting ephemeral plant growth in the desert ecosystem is water availability (Wang et al., 2004; Sun et al., 2009). Through a glasshouse experiment, the present study aimed to investigate the effects of soil water availability and AM fungi on the growth of ephemeral plants under different soil water conditions.

\section{Materials and methods}

\subsection{Plant and fungal species}

Two AM fungal species, Glomus mosseae BEG167 (G.m) and Glomus etunicatum BEG168 (G.e) were previously propagated in pot culture on maize (Zea mays) and clover (Trifolium pretense) plants grown in sand for 12 weeks. Inocula from the pot culture comprised a mixture of spores, mycelium, sand and maize and clover root fragments and contained approximately 1,000 spores per $100 \mathrm{~g}$.

Seeds of $P$. minuta were collected from the Gurbantunggut Desert in the Junggar Basin in May and June of 2004. The seeds were stored in $4^{\circ} \mathrm{C}$ until use. Before sowing, seeds were surface sterilized with $10 \%$ (v/v) hydrogen peroxide for $10 \mathrm{~min}$, washed with sterile water and germinated in the dark on moistened filter paper at $28^{\circ} \mathrm{C}$ for 3 days. Germinated seeds in uniform size were selected for planting.

Soil used in this experiment was collected from the Gurbantunggut Desert with the following properties: $\mathrm{pH}$ (water:soil ratio 5:1) 8.54, organic matter $1.43 \mathrm{~g} / \mathrm{kg}$, total salt $0.73 \mathrm{~g} / \mathrm{kg}$, available N $6.92 \mathrm{mg} / \mathrm{kg}$, Olsen P $1.78 \mathrm{mg} / \mathrm{kg}$, available $\mathrm{K} 73.00 \mathrm{mg} / \mathrm{kg}$ and electrical conduct $0.178 \mathrm{~ms} / \mathrm{cm}$. The soil was sieved (1-mm), steam-sterilized $\left(121^{\circ} \mathrm{C}\right.$ for $\left.30 \mathrm{~min}\right)$ and air-dried prior to potting.

\subsection{Experimental design}

The glasshouse experiment used a randomized block design consisting of three soil water regimes and three inoculation treatments. Soil water contents were $4.5 \%$, $9.0 \%$ and $15.75 \%$, equivalent to $20 \%, 40 \%$ and $70 \%$ of field capacity, respectively. Plants were inoculated with Glomus mosseae BEG167, Glomus etunicatum BEG168, or treated with non-inoculation, respectively. There were six replicate pots per treatment.

Fifty grams of fungal inoculum was mixed with $550 \mathrm{~g}$ of soil in each pot. Sterilized inoculum was used 
as non-inoculant control. Ten pre-germinated seeds of $P$. minuta were transplanted into each pot covered by another $50 \mathrm{~g}$ of non-inoculant sand. Seedlings were thinned to five per pot after emergence.

Plants were grown in a sunlit greenhouse with day/night temperature of $25-30^{\circ} \mathrm{C} / 18-22^{\circ} \mathrm{C}$. The soil water content was maintained by water to weight at 08:00 and 18:00 daily. Hoagland's nutrient solution with $1 / 2 \mathrm{P}$ was added every two weeks. Plants were harvested 8 weeks after sowing.

\subsection{Harvest and sample analysis}

Whole plant was harvested after 8 weeks sowed. Then, shoots and roots were separated. The roots were carefully washed free of soil. Sub-samples of roots were collected for determination of mycorrhizal colonization rate using the acid fuchsine staining-grid intersect method (Kormanik and McGraw, 1982). Both shoots and roots were dried at $70^{\circ} \mathrm{C}$ to determine dry weights. The tissue $\mathrm{N}$ concentration was determined by the Kjeldahl method; P concentration was measured with spectrophotometry by the molybdenum blue method after digested with concentrated $\mathrm{H}_{2} \mathrm{SO}_{4}$ and $30 \% \mathrm{H}_{2} \mathrm{O}_{2}$; and $\mathrm{K}$ concentrations was determined by flame photometry (Lu, 2000).

\subsection{Mycorrhizal dependency}

Mycorrhizal dependency at the given soil water content was calculated as:

Mycorrhizal dependency $(\%)=($ biomass of inoculated AM fungi-biomass of $\mathrm{CK}$ )/biomass of $\mathrm{CK} \times 100 \%$.
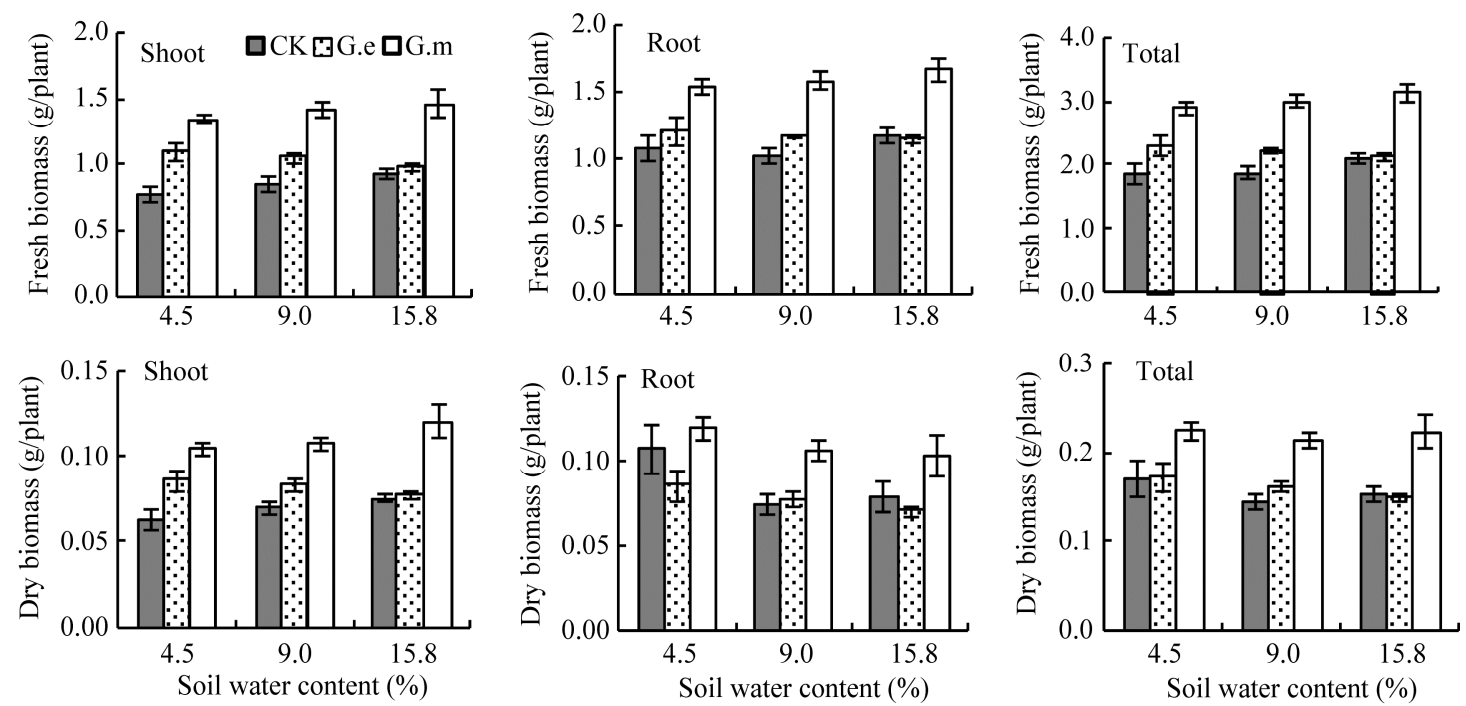

Fig. 1 Fresh and dry weights of Plantago minuta with different water and inoculation treatments. Data were means $\pm S E$ ( $n=6$ ). CK, non-inoculation treatment; G.e, Glomus etunicatum; G.m, Glomus mosseae.

\subsection{Statistical analysis}

The differences in percentage of root length colonized, of shoots and roots were subjected to one-way analysis of variance by least significant difference (LSD) at the $5 \%$ level for significantly differences between the means in all treatments using the SPSS software package version 16.0 (SPSS, Chicago IL). The effects of soil water content and AM fungi, and their interaction were subjected to two-way analysis of variance by the Univariate Analysis of Variance of General Linear Model.

\section{Results}

\subsection{Plant growth}

Both fresh and dry weights of plants (both shoots and roots) inoculated with G.m were significantly higher than those of the controls in all water treatments (Fig. 1). The fresh and dry weights of G.m-inoculated plants were 1.2, 1.4, and 1.5 times those of G.e treatment in $4.5 \%, 9.0 \%$ and $15.8 \%$ of soil water contents, respectively. When the effects of different AM fungi species were considered, biomass of G.m treatments was remarkably higher than these of G.e except for the dry weight of roots and whole plant in the treatment of $4.5 \%$ water. By comparing the same AM fungi treatments in different water conditions, there were not significant differences among them. The root to shoot ratio showed no significant difference between fungal species in the same water condition except for $4.5 \%$ water treatment (Fig. 2). shoot and root biomass, and N, P and $\mathrm{K}$ concentrations 


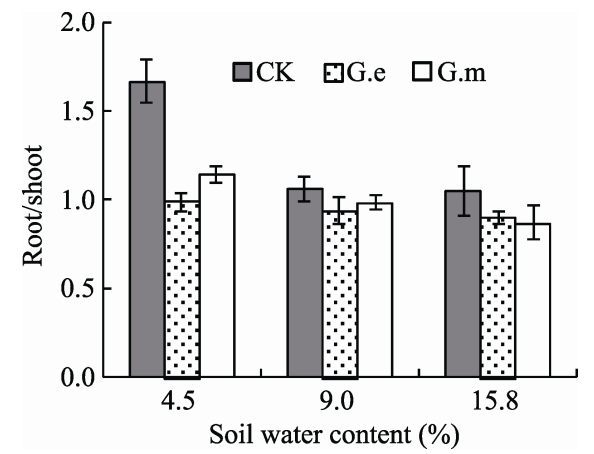

Fig. 2 The root to shoot ratio of dry weight of Plantago minuta with different water and inoculation treatments. Data were means \pm SE $(n=6)$. CK, non-inoculation treatment; G.e, Glomus etunicatum; G.m, Glomus mosseae.
AM fungi significantly increased plant biomass and the root/shoot ratio (Table 1). Soil water content influenced significantly dry biomass of roots and the ratio of root to shoot. Further, there was significant interaction between water and AM fungi on root/shoot mass ratio (Table 1).

\subsection{Mycorrhizal colonization rate}

In all water treatments, inoculated plants had higher colonization rates than the non-inoculation treatment $(F=475.39, P<0.001)$, with those inoculated with G.e under $4.5 \%$ soil water content (the highest is $15.8 \%$; Fig. 3). The colonization rate decreased significantly

Table 1 The effect of water and arbuscular mycorrhizal fungi on biomass of Plantago minuta

\begin{tabular}{|c|c|c|c|c|c|c|c|}
\hline \multirow{2}{*}{ Factor } & \multicolumn{3}{|c|}{ Fresh biomass } & \multicolumn{3}{|c|}{ Dry biomass } & \multirow{2}{*}{ Root/shoot } \\
\hline & Shoot & Root & Whole plant & Shoot & Root & Whole plant & \\
\hline Water & $\mathrm{ns}$ & ns & ns & ns & $* *$ & $\mathrm{~ns}$ & $* *$ \\
\hline AM fungi & $* *$ & $* *$ & $* *$ & $* *$ & $* *$ & $* *$ & $* *$ \\
\hline Water $\times$ AM fungi & $\mathrm{ns}$ & ns & ns & $\mathrm{ns}$ & $\mathrm{ns}$ & $\mathrm{ns}$ & $* *$ \\
\hline
\end{tabular}

Note: ** indicates significance at $P<0.01$ level; ns, not significant.

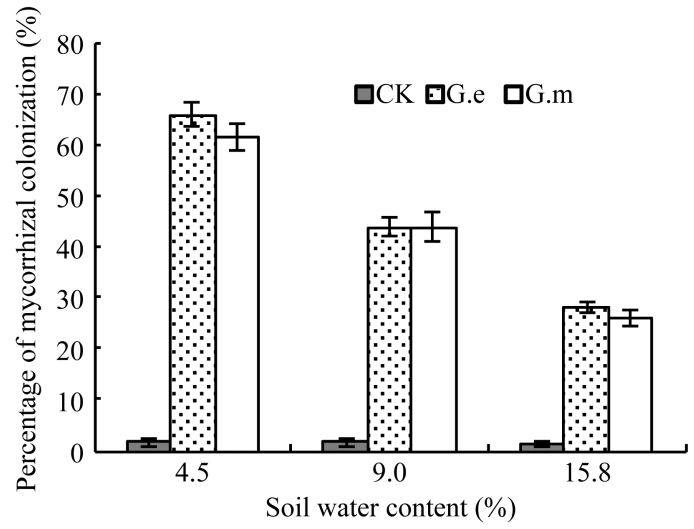

Fig. 3 Colonization rates of arbuscular mycorrrhizas in roots of Plantago minuta. Data were means \pm SE $(n=6)$. CK, non-inoculation treatment; G.e, Glomus etunicatum; G.m, Glomus mosseae. with the increase of soil water content $(F=116.98$, $P<0.001)$. AM fungi species, soil water content and their interactions affected significantly the mycorrhizal colonization rate of $P$. minuta $(F=26.70, P<0.01$; Fig. 3).

\subsection{Plant dependency on mycorrhiza}

In each soil water treatment, the based dependency of P. minuta to G.m was higher than that to G.e, respectively. The highest mycorrhizal dependency of shoots, roots and the whole plant in G.m was $83.3 \%$ (under $4.5 \%$ water treatment), $57.1 \%(9.0 \%$ water treatment), and $64.29 \%$ (15.8\% water treatment), respectively.

Table 2 The dependency of Plantago minuta to AM fungi in different soil water treatments

\begin{tabular}{|c|c|c|c|c|}
\hline \multicolumn{2}{|c|}{ Treatments } & \multicolumn{3}{|c|}{ Mycorrhizal dependency (\%) } \\
\hline Soil water content $(\%)$ & AM fungi & Shoot & Root & Whole plant \\
\hline \multirow[t]{3}{*}{4.5} & $\mathrm{CK}$ & 0.00 & 0.00 & 0.00 \\
\hline & Glomus etunicatum & 33.33 & 37.50 & 35.71 \\
\hline & G. mosseae & 83.33 & 50.00 & 64.29 \\
\hline \multirow[t]{3}{*}{9.0} & $\mathrm{CK}$ & 0.00 & 0.00 & 0.00 \\
\hline & Glomus etunicatum & 14.29 & 14.29 & 14.29 \\
\hline & G. mosseae & 57.14 & 57.14 & 57.14 \\
\hline \multirow[t]{3}{*}{15.8} & $\mathrm{CK}$ & 0.00 & 0.00 & 0.00 \\
\hline & Glomus etunicatum & 0.00 & 12.50 & 0.00 \\
\hline & G. mosseae & 50.00 & 25.00 & 46.67 \\
\hline
\end{tabular}




\subsection{The nutrient concentration of $P$. minuta}

The shoot $\mathrm{P}$ and root $\mathrm{K}$ of inoculated plants were significantly higher than those of non-mycorrhizal controls in each soil water condition (Fig. 4). Shoot N and $\mathrm{K}$ concentration followed the similar trend as root $\mathrm{P}$ concentration, i.e. significantly higher concentration in the G.m-inoculated plants than in the non-mycorrhizal controls, respectively. However, plants inoculated with G.e affected shoot $\mathrm{N}$ and $\mathrm{K}$ and root $\mathrm{P}$ concentrations compared to non-inoculated treatments. The root $\mathrm{N}$ concentrations of inoculated plants were higher than that in controls under $4.5 \%$ and $9.0 \%$ soil water conditions. The changes of nutrient concentration either in shoots or in roots were not significant among varied soil water content regardless of the difference of AM fungi species.

When the water and AM fungi were considered simultaneously, AM fungi increased markedly the N, $\mathrm{P}$ and $\mathrm{K}$ concentration of $P$. minuta in both shoots and roots (Table 3 ). However, soil water content influenced significantly $\mathrm{P}$ in shoots and $\mathrm{N}$ and $\mathrm{K}$ in roots. Further, the interaction of water and AM fungi affected remarkably the P concentrations in shoots and $\mathrm{K}$ concentrations in roots (Table 3 ).

\section{Discussion and conclusion}

This study examined the combined effects of soil water content and AM fungi colonization on a desert spring ephemeral plant. Our results showed that AM fungi played vital roles in growth and nutrition absorption under varying soil water conditions, which indicated that the effects of AM fungi to $P$. minuta did not depend on soil water content given in this experiment. However, Wang et al. (2004) reported that the coverage of desert ephemeral plants presented a positive correlation with soil water content at a range from $0.45 \%$ to $4.92 \%$ based on a filed investigation in the Gurbantunggut Desert. The possible reason is AM fungi can help host plants to uptake enough water for their growth even under drought condition because AM fungi can increase the absorption area of hosts ( $\mathrm{Li}$ et al., 1991). Additionally, the colonization rate decreased with the increase of soil water content in our study.
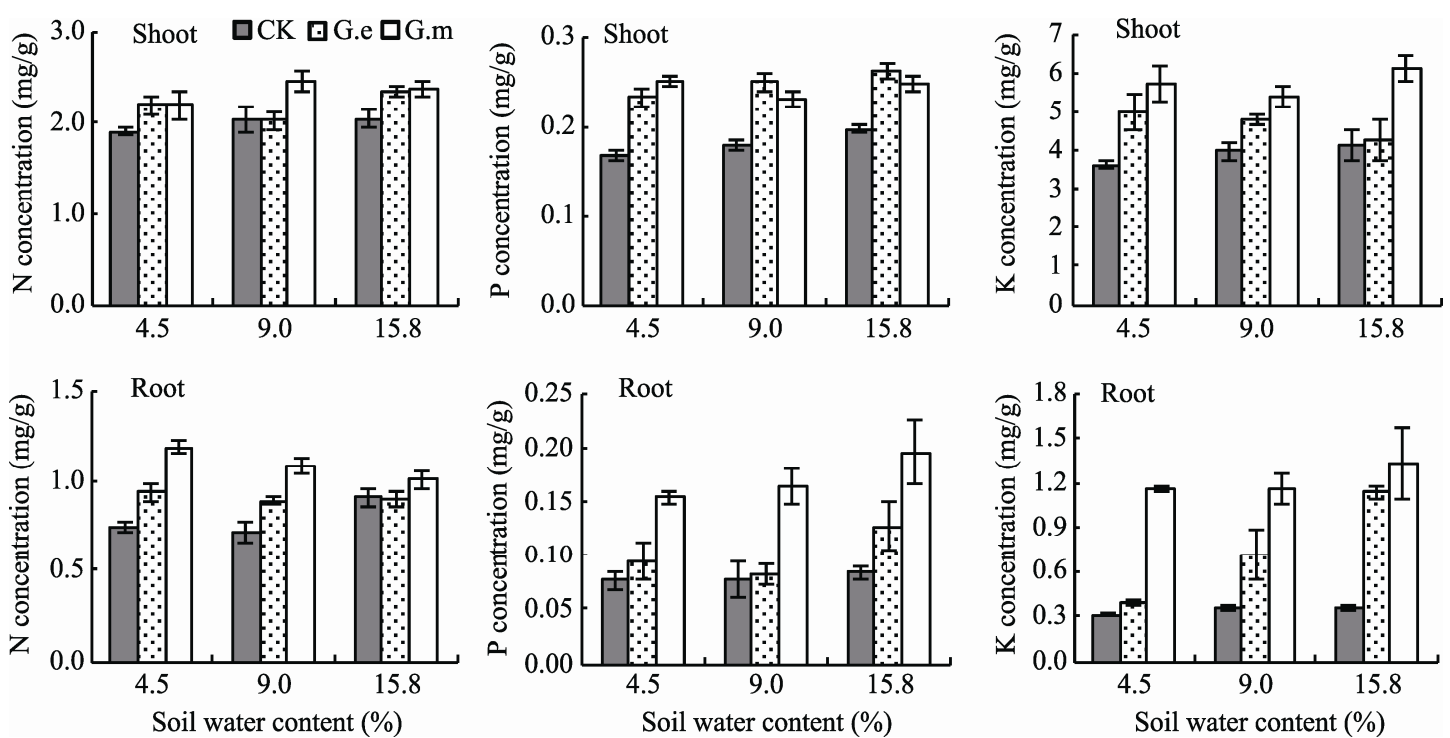

Fig. 4 Concentrations of N, P and K of Plantago minuta of different treatments by water and arbuscular mycorrhizal fungi. Data were means \pm SE $(n=6)$. CK, non-inoculation treatment; G.e, Glomus etunicatum; G.m, Glomus mosseae.

Table 3 The effect of water and arbuscular mycorrhizal fungi on nutrient concentration of Plantago minuta

\begin{tabular}{|c|c|c|c|c|c|c|}
\hline \multirow{2}{*}{ Factor } & \multicolumn{3}{|c|}{ Shoot } & \multicolumn{3}{|c|}{ Root } \\
\hline & $\mathrm{N}$ & $\mathrm{P}$ & $\mathrm{K}$ & $\mathrm{N}$ & $\mathrm{P}$ & $\mathrm{K}$ \\
\hline Water & $\mathrm{ns}$ & $* *$ & ns & * & $\mathrm{ns}$ & $* *$ \\
\hline AM fungi & $* *$ & $* *$ & $* *$ & $* *$ & $* *$ & $* *$ \\
\hline Water $\times$ AM fungi & ns & $* *$ & ns & $\mathrm{ns}$ & ns & $* *$ \\
\hline
\end{tabular}

Note: $*$ and $* *$ indicate significances at $P<0.05$ and $P<0.01$ levels, respectively; ns, not significant. 
Many studies have showed that AM fungi colonization rate decreased under the water stress comparing to the normal water conditions (Khalvati et al., 2010; Ruiz-Lozano and Aroca, 2010; Jayne and Quigley, 2014). However, our results indicated that the mycorrhizal colonization of ephemeral plant $P$. minuta declined with the increase of the soil water content (Fig. $3)$. The lowest soil water content $(4.5 \%)$ in the present study was close to the natural field water condition (Shi et al., 2013). The habitats of ephemerals are extremely adverse with low nutrient content of the substrate (quicksand) and low water content $(2 \%-5 \%)$ in the top $30 \mathrm{~cm}$ of the sandy soil layer due to the lack of rainfall (annual precipitation of 100-120 mm) (Ji et al., 1995). In soil water deficit conditions, $P$. minuta may need to depend on AM fungi for accessing water directly through the hyphal network helping the host plant to survive in the adverse desert environment. In addition, the colonization rate of $P$. minuta was similar to that under natural field conditions $(55 \% \pm 8 \%)$ reported previously (Shi et al., 2006). With the increase of soil water content, the function provided by the AM fungi pathway in accessing soil water to alleviate plant water stress was not thus required. Further, the results of mycorrhizal dependency supported this conclusion (Table 2).

It is widely reported AM fungi can enhance the host plant growth and development whilst improving nutrient status of the host plant. Researchers show AM fungi can assist desert ephemeral plants by increasing the growth, development and nutrient status of the host plants (Chen et al., 2008; Sun et al., 2008; Zhang et al., 2011). Our results also showed that AM fungi can increase plant growth and nutrient concentrations (particularly P status). Biomass and nutrient concentrations of inoculated plants were not necessarily significantly higher than those of controls (Figs. 1 and 4), as the case in a report of Treseder (2013). In addition, plant growth was improved by AM fungi colonization with variation among AM fungi and among different water treatments. AM fungi significantly increased biomass and the concentrations of N, P and $\mathrm{K}$ in both shoots and roots, indicating their important nutritional role regardless of water conditions imposed in this study. This finding is consistent with a meta-analysis of Jayne and Quigley (2014). That is to say, the effect of AM fungi on plants of the high watered treatments was not different from that of the low water treatment. When inoculated with AM fungi, the low-water treated plants grew as well as those under high-water conditions.

When the effects of water were considered, we found that higher soil water content did not suppress root dried biomass and the root/shoot ratio, but improved $\mathrm{P}$ concentration in shoots and $\mathrm{N}$ and $\mathrm{K}$ concentrations in roots. Further, plants depended on more roots for foraging water in drought condition than in well watered condition. Except for shoot $\mathrm{P}$ and root $\mathrm{N}$ and $\mathrm{K}$, the influence of AM fungal inoculation had no significantly effect on other nutrient elements. Sun et al. (2009) showed that different host plants had various effects in $\mathrm{N}, \mathrm{P}$ and $\mathrm{K}$ acquisition under different water treatments.

In conclusion, although the AM fungi dependency of $P$. minuta decreased with the increase of soil water content, the functions of AM fungi to $P$. minuta are not suppressed by improving soil available water. We inferred that the AM fungi is a vital factor for ephemeral plants to adapt to adverse soil water-deficit desert environment that is formed during the evolution process based on an equal term of trade agreement.

\section{Acknowledgements}

This work was funded by the Foundation for University Key Teacher by Henan Educational Committee (2013GGJS070), the National Basic Research Program of China (2014CB954202), the National Natural Science Foundation of China (40971150) and the China Scholarship Council (201208410020).

\section{References}

Allen M F. 2011. Linking water and nutrients through the vadose zone: a fungal interface between the soil and plant systems. Journal of Arid Land, 3: 155-163.

Apple M E. 2010. Aspects of mycorrhizae in desert plants. In: Ramawat K G. Desert Plants. Berlin: Springer, 121-134.

Augé R M. 2004. Arbuscular mycorrhizae and soil/plant water relations. Canadian Journal of Soil Science, 84: 373-381.

Chen Z C, Shi Z Y, Tian C Y, et al. 2008. Effects of arbuscular mycorrhizal fungal inoculation on growth and nutrient uptake of two ephemeral plants. Chinese Journal of Plant Ecology, 32: 648-653. (in Chinese)

Jayne B, Quigley M. 2014. Influence of arbuscular mycorrhiza on growth and reproductive response of plants under water deficit: a meta-analysis. Mycorrhiza, 24: 109-119.

Ji F, Fan Z L, Zhao H G. 1995. Comparison of the physical-chemical 
characteristics of Aeolian soils in the Taklamakan desert and the Gurbantunggut desert. Arid Zone Research, 12: 21-25. (in Chinese)

Kaschuk G, Kuyper T W, LeVelaar P A, et al. 2009. Are the rates of photosynthesis stimulated by the carbon sink strength of rhizobial and arbuscular mycorrhizal symbioses? Soil Biology \& Biochemistry, 41: 1233-1244.

Khalvati M, Bartha B, Dupigny A, et al. 2010. Arbuscular mycorrhizal association is beneficial for growth and detoxification of xenobiotics of barley under drought stress. Journal of Soils Sediments, 10: 54-64.

Kiers E T, Duhamel M, Beesetty Y, et al. 2011. Reciprocal rewards stabilize cooperation in the mycorrhizal symbiosis. Science, 333: 880-882.

Kormanik P P, McGraw A C. 1982. Quantification of vesiculararbuscular mycorrhizae in plant roots. In: Schenk S C. Methods and Principles of Mycorrhisat Research. St Paul: American Phytopathological Society, 37-45.

Lambers H F, Chapin S, Pons T L. 2008. Plant Physiological Ecology. New York: Springer.

Lan H Y, Zhang F C. 2008. Reviews on special mechanisms of adaptability of early-spring ephemeral plants to desert habitats in Xinjiang. Acta Botanica Boreali-Occidentalia Sinica, 28: 1478-1485. (in Chinese)

Li X L, George E, Marschner H. 1991. Extension of the phosphorus depletion zone in VA-mycorrhizal white clover in a calcareous soil. Plant and Soil, 136: 41-48.

Lu R K. 2000. The Analytical Methods for Soil and Agrochemistry. Beijing: China Agricultural Science and Technology Press. (in Chinese)

Mao Z M, Zhang D M. 1994. The conspectus of ephemeral flora in northern Xinjiang. Arid Zone Research, 11: 1-26. (in Chinese)

Qian Y B, Wu Z N, Yang Q, et al. 2007. Ground-surface conditions of sand-dust event occurrences in the southern Junggar Basin of Xinjiang, China. Journal of Arid Environments, 70: 49-62.

Ramawat K G. 2010. Desert Plants: Biology and Biotechnology. New York: Springer.

Ruiz-Lozano J M, Aroca R. 2010. Host response to osmotic stresses: stomatal behaviour and water use efficiency of arbuscular mycorrhizal plants. In: Koltai H, Kapulnik Y. Arbuscular Mycorrhizas: Physiology and Function. Berlin: Springer, 239-256

Shi Z Y, Feng G, Christie P, et al. 2006. Arbuscular mycorrhizal status of spring ephemerals in the desert ecosystem of Junggar Basin, China. Mycorrhiza, 16: 269-275.

Shi Z Y, Zhang L Y, Li X L, et al. 2007. Diversity of arbuscular mycorrhizal fungi associated with desert ephemerals in plant communities of Junggar Basin, northwest China. Applied Soil Ecology, 35: 10-20.

Shi Z Y, Liu D H, Wang F Y. 2013. Spatial variation of arbuscular mycorrhizal fungi in two vegetation types in gurbantonggut desert. Contemporary Problems of Ecology, 6: 455-464.

Smith S E, Read D J. 2008. Mycorrhizal Symbiosis. Boston: Boston Academic Press.

Smith S E, Facelli E, Pope S, et al. 2010. Plant performance in stressful environments: interpreting new and established knowledge of the roles of arbuscular mycorrhizas. Plant and Soil, 326: 3-20.

Sun Y, Li X L, Feng G. 2008. Effect of arbuscular mycorrhizal fungi colonization on ecological functional traits of ephemerals in Gurbantonggut desert. Symbiosis, 46: 121-127.

Sun Y, Zhang T, Tian C Y, et al. 2009. Response of grass growth and productivity to enhanced water input in ephemeral desert grassland in Gurbantunggut desert. Acta Ecologica Sinica, 29: 1859-1868. (in Chinese)

Treseder K K. 2013. The extent of mycorrhizal colonization of roots and its influence on plant growth and phosphorus content. Plant and Soil, 371: 1-13.

van der Heijden M G A, Streitwolf-Engel R, Riedl R, et al. 2006. The mycorrhizal contribution to plant productivity, plant nutrition and soil structure in experimental grassland. New Phytologist, 172: 739-752.

Wang X Q, Jiang J, Lei J Q, et al. 2003. The distribution of ephemeral vegetation on the longitudinal dune surface and its stabilization significance in the Gurbantunggut Desert. Acta Geographica Sinica, 58: 598-605. (in Chinese)

Wang X Q, Jiang J, Lei J Q, et al. 2004. Relationship between spring ephemeral plants distribution and soil moisture on longitudinal dune surface in Gurbantunggut desert. Chinese Journal Applied Ecology, 15: 556-560. (in Chinese)

Wang X Q, Zhang Y, Jiang J, et al. 2009. Effects of spring-summer grazing on longitudinal dune surface in southern Gurbantunggut Desert. Journal of Geographical Science, 19: 299-308.

Yuan S F, Tang H P. 2010. Research advances in the eco-physiological characteristics of ephemerals adaptation to habitats. Acta Prataculturae Sinica, 19: 240-247. (in Chinese)

Zhang L, Chen C. 2002. On the general characteristics of plant diversity of Gurbantunggut sandy desert. Acta Ecologica Sinica, 22: 1923-1932. (in Chinese)

Zhang T, Sun Y, Song Y C, et al. 2011. On-site growth response of a desert ephemeral plant, Plantago minuta, to indigenous arbuscular mycorrhizal fungi in a central Asia desert. Symbiosis, 55: 77-84.

Zhang T, Sun Y, Shi Z Y, et al. 2012a. Arbuscular mycorrhizal fungi can accelerate the restoration of degraded spring grassland in Central Asia. Rangeland Ecology \& Management, 65: 426-432.

Zhang T, Tian C Y, Sun Y, et al. 2012b. Dynamics of arbuscular mycorrhizal fungi associated with desert ephemeral plants in Gurbantunggut Desert. Journal of Arid Land, 4: 43-51. 